\title{
A multicenter study of body mass index in cancer patients treated with anti-PD-1/PD-L1 immune checkpoint inhibitors: when overweight becomes favorable
}

Alessio Cortellini ${ }^{1,2,23^{*}}$ (D), Melissa Bersanelli, ${ }^{3,4}$, Sebastiano Buti ${ }^{3}$, Katia Cannita ${ }^{2}$, Daniele Santini ${ }^{5}$, Fabiana Perrone ${ }^{3}$, Raffaele Giusti ${ }^{6}$, Marcello Tiseo ${ }^{3,4}$, Maria Michiara ${ }^{3}$, Pietro Di Marino ${ }^{7}$, Nicola Tinari ${ }^{8}$, Michele De Tursi ${ }^{8}$, Federica Zoratto ${ }^{9}$, Enzo Veltri ${ }^{9}$, Riccardo Marconcini ${ }^{10}$, Francesco Malorgio ${ }^{11}$, Marco Russano ${ }^{5}$, Cecilia Anesi ${ }^{5}$, Tea Zeppola ${ }^{5}$, Marco Filetti ${ }^{6}$, Paolo Marchetti ${ }^{6,12}$, Andrea Botticelli ${ }^{6}$, Gian Carlo Antonini Cappellini ${ }^{12}$, Federica De Galitiis ${ }^{12}$, Maria Giuseppa Vitale ${ }^{13}$, Francesca Rastelli ${ }^{14}$, Federica Pergolesi ${ }^{14}$, Rossana Berardi ${ }^{15}$, Silvia Rinaldi ${ }^{15}$, Marianna Tudini ${ }^{16}$, Rosa Rita Silva ${ }^{16}$, Annagrazia Pireddu ${ }^{17}$, Francesco Atzori ${ }^{17}$, Rita Chiari ${ }^{18}$, Biagio Ricciuti ${ }^{18}$, Andrea De Giglio ${ }^{18}$, Daniela lacono ${ }^{19}$, Alain Gelibter $^{20}$, Mario Alberto Occhipinti ${ }^{20}$, Alessandro Parisi ${ }^{1,2}$, Giampiero Porzio ${ }^{1,2}$, Maria Concetta Fargnoli ${ }^{21,2}$, Paolo Antonio Ascierto ${ }^{22}$, Corrado Ficorella ${ }^{1,2}$ and Clara Natoli ${ }^{8}$

\section{Abstract}

Background: Recent evidence suggested a potential correlation between overweight and the efficacy of immune checkpoint inhibitors (ICls) in cancer patients.

Patients and methods: We conducted a retrospective study of advanced cancer patients consecutively treated with anti-PD-1/PD-L1 inhibitors, in order to compare clinical outcomes according to baseline BMl levels as primary analysis. Based on their BMl, patients were categorized into overweight/obese $(\geq 25)$ and non-overweight $(<25)$. A gender analysis was also performed, using the same binomial cut-off. Further subgroup analyses were performed categorizing patients into underweight, normal weight, overweight and obese.

Results: Between September 2013 and May 2018, 976 patients were evaluated. The median age was 68 years, male/female ratio was 663/313. Primary tumors were: NSCLC (65.1\%), melanoma (18.7\%), renal cell carcinoma (13.8\%) and others (2.4\%). ECOG-PS was $\geq 2$ in 145 patients (14.9\%). PD-1/PD-L1 inhibitors were administered as first-line treatment in $26.6 \%$ of cases. Median BMI was 24.9: 492 patients (50.6\%) were non-overweight, 480 patients (50.4\%) were overweight/obese. $25.2 \%$ of non-overweight patients experienced irAEs of any grade, while $55.6 \%$ of overweight/obese patients $(p<0.0001)$. ORR was significantly higher in overweight/obese patients compared to non-overweight ( $p<0.0001$ ). Median follow-up was 17.2 months. Median TTF, PFS and OS were significantly longer for overweight/obese patients in univariate $(p<0.0001$, for all the survival intervals) and multivariate models $(p=0.0009, p<0.0001$ and $p<0.0001$ respectively). The significance was confirmed in both sex, except for PFS in male patients $(p=0.0668)$.

* Correspondence: alessiocortellini@gmail.com

${ }^{1}$ Medical Oncology, St. Salvatore Hospital, L'Aquila, Italy

2Department of Biotechnological and Applied Clinical Sciences, University of

L'Aquila, L'Aquila, Italy

Full list of author information is available at the end of the article

(c) The Author(s). 2019 Open Access This article is distributed under the terms of the Creative Commons Attribution 4.0 International License (http://creativecommons.org/licenses/by/4.0/), which permits unrestricted use, distribution, and reproduction in any medium, provided you give appropriate credit to the original author(s) and the source, provide a link to the Creative Commons license, and indicate if changes were made. The Creative Commons Public Domain Dedication waiver (http://creativecommons.org/publicdomain/zero/1.0/) applies to the data made available in this article, unless otherwise stated. 
(Continued from previous page)

Conclusions: Overweight could be considered a tumorigenic immune-dysfunction that could be effectively reversed by ICls. BMI could be a useful predictive tool in clinical practice and a stratification factor in prospective clinical trials with $\mathrm{ICls}$.

Keywords: BMI, Anti-PD-1/PD-L1, Overweight, Obesity, Cancer, Immunotherapy

\section{Key message}

Recent evidence revealed that adipose tissue might affect the response to immune checkpoint inhibitors (ICIs) in cancer patients. In this retrospective transverse study, enrolling 976 advanced cancer patients treated with anti-PD-1/PD-L1 immunotherapy, we found a significant association between overweight $(\mathrm{BMI} \geq 25)$ and improved clinical outcomes to ICIs.

\section{Introduction}

Although the interaction between malnutrition and chronic inflammation has been widely investigated, whether this association is causative or correlative is still debated [1] Historically, body mass index (BMI) has been considered the major surrogate of nutritional status and its correlation with clinical outcomes in advanced cancer patients has already been investigated without conclusive results [2-5].

It is now becoming clear that the nutritional assessment, which should include BMI, could be seen in a "new light" in the era of immune checkpoint inhibitors (ICIs). A large retrospective study has recently found an association between BMI and improved progression free survival (PFS) and overall survival (OS) in melanoma patients treated with either targeted therapy or immunotherapy [6]. Another study has reported that overweight sarcopenic melanoma patients treated with anti-PD1 (Programmed cell death protein 1) inhibitors experienced early acute limiting toxicity [7].

Additionally, another retrospective analysis by Richtig et al. revealed that overweight $(\mathrm{BMI} \geq 25)$ melanoma patients (76 total) treated with ipilimumab had significantly higher response rate $(\mathrm{p}=0.024)$ and a trend for longer OS $(\mathrm{p}=$ 0.056), when compared to non-overweight patients [8].

Lastly, Wang and colleagues have recently reported an improvement in terms of PFS $(\mathrm{p}=0.003)$ and OS $(\mathrm{p}=0.049)$ in a cohort of obese advanced cancer patients $(\mathrm{BMI} \geq 30)$ treated with ICIs [9].

To further dissect this question, we conducted a large, multicentre, retrospective transverse study to evaluate clinical outcomes of patients with advanced solid tumors treated with ICIs according to baseline BMI.

\section{Materials and methods}

\section{Patient eligibility}

This study enrolled patients with confirmed diagnosis of measurable stage IV cancer, who consecutively underwent treatment with single agent anti-PD-1/PD-L1 as $1^{\text {st }}$ or subsequent line, at the medical oncology departments of 17 Italian centers (Additional file 1), between September 2013 and May 2018.

\section{Anthropometric measurements}

Weight and height were obtained from the patient's medical records at the time of immunotherapy initiation. BMI was calculated using the formula of weight/height ${ }^{2}$ (kilograms per square meter) and classified according to the World Health Organization (WHO) categories: underweight, $\mathrm{BMI}<18.5$; normal, $18.5 \leq \mathrm{BMI} \leq 24.9$; overweight, $25 \leq \mathrm{BMI} \leq 29.9$; obesity, $\mathrm{BMI} \geq 30$. For the study purpose, the binomial cut-off for BMI $</ \geq 25$ was used, and patients were categorized into non-overweight $(<25)$ and overweight/obese $(\geq 25)$ for the final analysis. Underweight patients were included in the non-overweight group.

\section{Study design}

We conducted a "real-life", multicenter, retrospective observational study aimed at comparing the clinical outcomes of cancer patients treated with ICIs according to baseline BMI levels.

Primary outcomes measures were: objective response rate (ORR), time to treatment failure (TTF), PFS and OS. ORR was defined as the proportion of patients experiencing an objective response (either complete response or partial response) as best response to immunotherapy. TTF was defined as the time from treatment's start to discontinuation for any reason. Progression-free survival (PFS) was defined as the time from the start of immunotherapy to the date of disease progression or death, whichever occurred first. Patients who were alive without disease progression were censored on the date of their last disease assessment. Overall survival (OS) was defined as the time from the start of immunotherapy to death. Patients who were still alive were censored at the date of last contact. Patients were treated according to the tumor type indication with pembrolizumab, nivolumab or atezolizumab with standard doses and schedules.

In order to weighing the possible prognostic influence of obesity (30 BMI) and malnutrition (or cachexia), two subgroup analysis (according to each BMI categories) were performed. In the first one, overweight (25-30 BMI) 
and obese ( $\geq 30 \mathrm{BMI}$ ) patients were respectively compared to non-overweight $(<25)$ patients, in the second one overweight (25-30 BMI) and obese ( $\geq 30 \mathrm{BMI})$ patients were respectively compared to normal weight patients (18.5-25 BMI).

A subgroup analysis comparing clinical outcomes in males and females patients, using the binomial cut-off $(\mathrm{BMI}</ \geq 25)$ was also conducted as secondary analysis.

The following covariates were considered for the multivariate analyses: primary tumor (NSCLC, melanoma, kidney and others), sex (male $v s$ female), Eastern Cooperative Oncology Group Performance Status (ECOG-PS) $(0-1 v s . \geq 2)$, age $(<70 v s . \geq 70$ years old $)$ [10-13], number of metastatic sites $(\leq 2 v s .>2)$ and treatment line (first $v s$ non-first). As in some indications the anti-PD-1/PD-L1 agents dosages had been weightbased, weight was used as a continuous covariate in all the analyses, considering the possible dose-depending confounding effect on the clinical outcomes.

Immune-related AEs (irAEs) were graduated according to the Common Toxicity Criteria for Adverse Events (CTCAE; version 4.0) and cumulatively reported. Immune-related AEs were categorized on the basis of the organ/system involved as follows: endocrine irAEs (including thyroid disorders), gastro-intestinal (GI) irAEs (excluding pancreatitis), skin irAEs, pneumological irAEs, hepatic irAEs, rheumatologic irAEs and others irAEs (including neuro-muscolar, pancreatitis, fever, asthenia and anorexia). The safety analysis was performed for irAEs of any grade and for G3/G4 irAEs.

To determine ORR and PFS, scans were reviewed by a dedicated thoracic oncologist at each Institution using Response Evaluation Criteria In Solid Tumors (RECIST) version 1.1. [14]. $\chi^{2}$ was used to compare ORR and incidence of irAEs among subgroups [15]. In the multivariate analysis, logistic regression was used to evaluate the role of parameters proven to be significant at the univariate analysis of ORR [16]. Median TTF, median PFS, and median OS were evaluated using the Kaplan-Meier method [17]. Median follow-up was calculated according to the reverse Kaplan-Meier method [18]. Cox proportional hazards model [19] was used to evaluate predictor variables in univariate and multivariate analysis for TTF, PFS and OS. The data cut-off was October $29^{\text {th }}, 2018$. All statistical analyses were performed using MedCalc Statistical Software version 18.6 (MedCalc Software bvba, Ostend, Belgium; http://www.medcalc.org; 2018).

\section{Results}

\section{Patient characteristics}

Nine hundred and seventy-six, consecutive advanced cancer patients were evaluated. Patient characteristics are summarized in Table 1 . The median age was 68 years (range: $24-92$ ), male/female ratio was $663 / 313$. Primary
Table 1 Patients' characteristics

\begin{tabular}{|c|c|}
\hline & $\mathrm{N}^{\circ}(\%)$ \\
\hline & 976 \\
\hline \multicolumn{2}{|l|}{ AGE, (years) } \\
\hline Median & 68 \\
\hline Range & 24-92 \\
\hline Elderly ( $\geq 70$ ) & $445(45.6)$ \\
\hline \multicolumn{2}{|l|}{ SEX } \\
\hline Male & $663(67.9)$ \\
\hline Female & $313(32.1)$ \\
\hline \multicolumn{2}{|l|}{ ECOG PS } \\
\hline $0-1$ & $831(85.1)$ \\
\hline$\geq 2$ & $145(14.9)$ \\
\hline \multicolumn{2}{|l|}{ Primary Tumor } \\
\hline NSCLC & $635(65.1)$ \\
\hline Melanoma & $183(18.7)$ \\
\hline Renal cell carcinoma & $135(13.8)$ \\
\hline Others & $23(2.4)$ \\
\hline \multicolumn{2}{|l|}{ No. of metastatic sites } \\
\hline$\leq 2$ & $467(47.9)$ \\
\hline$>2$ & $509(52.1)$ \\
\hline \multicolumn{2}{|l|}{ Type of anti-PD-1/PD-L1 agent } \\
\hline Pembrolizumab & $235(24.1)$ \\
\hline Nivolumab & $706(72.3)$ \\
\hline Atezolizumab & $35(3.6)$ \\
\hline \multicolumn{2}{|l|}{ Treatment line of Immunotherapy } \\
\hline First & $260(26.6)$ \\
\hline Non-First & $716(73.4)$ \\
\hline \multicolumn{2}{|l|}{ Weight (Kg) } \\
\hline Median & 71 \\
\hline Range & $35-139$ \\
\hline \multicolumn{2}{|l|}{ BMI $\left(\mathrm{kg} / \mathrm{m}^{2}\right)$} \\
\hline Median (range) & $24.9(13.5-46.6)$ \\
\hline Underweight (BMI $\leq 18.5), \mathrm{n}^{\circ}(\%)$ & $40(4.1)$ \\
\hline Normal weight (BMI $18.5<\mathrm{BMI} \leq 24.9), \mathrm{n}^{\circ}(\%)$ & $452(46.3)$ \\
\hline Overweight (25 < BMI $\leq 29.9), \mathrm{n}^{\circ}(\%)$ & $377(38.6)$ \\
\hline Obese (BMI $\geq 30), n^{\circ}(\%)$ & $107(11)$ \\
\hline
\end{tabular}

tumors were: NSCLC (635 patients), melanoma (183 patients), renal cell carcinoma (135 patients) and others (23 patients). ECOG-PS was 0/1 in 831 patients (85.1\%), and $\geq 2$ in 145 patients (14.9\%); 467 patients $(47.9 \%)$ had $\leq 2$ metastatic sites while 509 (52.1\%) had more than 2 metastatic sites. PD-1/PD-L1 inhibitors were administered as first-line treatment in 260 patients (26.6\%). Median weight was $71 \mathrm{Kg}$, median BMI was 24.9; according to WHO classification 40 patients (4.1\%) were defined as underweight, 452 patients (46.3\%) as having a 
normal weight, 377 patients (38.6\%) as overweight and 107 patients $(11 \%)$ as obese. For the study purpose, 492 patients were considered as non-overweight (50.4\%) and 484 patients were categorized as overweight/obese (49.6\%) according to a BMI cut-off of $25(<25 v s$. $\geq 25)$.

Among male patients median age was 69 years, median weight was $72 \mathrm{Kg}$ (range: 35 - 139) and median BMI was 24.8 (range: 14 - 46.6). Among female patients median age was 67, median weight was $70 \mathrm{Kg}$ (range: $40-130$ ) and median BMI was 25.4 (range: 13.6 - 46.1).

\section{Safety analysis}

In the entire cohort, 393 patients (40.3\%) experienced irAEs of any grade. Sixty-three patients (6.5\%) experienced G3/G4 irAEs. Overweight/obese patients were significantly more likely to experience any grade irAEs compared to non-overweight patients $(55.6 \%$ vs. $25.2 \%$, $\mathrm{p}<0.0001$ ). However, no difference in the rate of G3/G4 irAEs was observed between Overweight/obese patients and non-overweight patients (7.6 vs. $5.3 \%, \mathrm{p}=0.1338$ ). The safety profile of ICIs according to BMI is summarized in Additional file 2.

\section{Activity analysis}

Univariate and multivariate analyses for ORR are detailed in Additional file 3. Among 910 patients evaluable for activity, 283 patients had a response to ICIs (ORR: $31.1 \%)$. Overweight/obese patients had a significantly higher ORR compared non-overweight patients $(41.3 \%$ vs. $20.9 \%, \mathrm{p}<0.0001)$. Similarly, we found a significantly higher ORR among patients who experienced at least 1 irAE compared to those without irAEs $(45.1 \%$ vs. $21.1 \%, \mathrm{p}<0.0001$ ). Both BMI (overweight/obese vs. non-overweight) and the development of irAEs of any grade, were independently associate with higher ORR in the multivariate analysis $(\mathrm{p}=0.0239$ and $\mathrm{p}<0.0001$, respectively).

\section{Efficacy analysis}

At median follow-up of 17.2 months, median TTF was 5.9 months (95\% CI: 5.3 - 6.7; 681 events), median PFS was 6.5 months (95\% CI: 6.1 - 7.1; 644 events) and median OS was 13.4 months (95\% CI: 11.0 - 16.5; 488 censored patients) in the entire cohort.

When these outcomes where analyzed according to BMI, we found that median TTF was significantly longer in overweight/obese patients compared to non-overweight patients (9.3 [95\% CI: 8.1 - 11.6; 318 events] vs. 3.6 months [95\% CI: $3.2-4.1 ; 363$ events]; $\mathrm{HR}=0.51$ [95\% CI: $0.44-0.60], \mathrm{p}<0.0001$ ) (Fig. 1a). Similarly, median PFS was significantly improved in the overweight/obese group compared to the non-overweight group (11.7 months [95\% CI: $9.4-15 ; 286$ events] vs. 3.7 months [95\% CI: $3.2-4.1 ; 358$ events]; $\mathrm{HR}=0.46$ [95\%CI: 0.39 - 0.54], p < 0.0001) (Fig. 1b). Consistently we also found a significantly prolonged median OS among overweight/obese patients compared to non-over weight patients ( 26.6 months [95\% CI: $21.4-36.8$; 286 censored patients] vs. 6.6 months [95\% CI: 5.8 - 8.5; 182 censored patients]; $\mathrm{HR}=0.33$ [95\%CI: $0.28-0.41$ ], $\mathrm{p}<0.0001$ ) (Fig. 1c).

After adjusting for PS, treatment line, $\mathrm{n}^{\circ}$ of metastatic sites, gender, primary tumor subtype and development of irAEs, a BMI of $\geq 25$ retained a significant association with a longer TTF $(\mathrm{p}=0.0009)$, PFS $(\mathrm{p}<0.0001)$ and OS $(\mathrm{p}<0.0001)$ in multivariate models (Table 2, Table 3 , Table 4)

\section{Subgroup analyses}

Table 5 reports the univariate and multivariate gender analyses for TTF, PFS and OS of male patients (Table 5A) and female patients (Table 5B). As shown overweight/obese male patients had significantly longer TTF $(p=0.0330)$ and OS ( $p=0.0013)$, but not PFS ( $p=0.0668)$, when compared with non-overweight patients, while overweight/obese female patients had significantly longer TTF $(\mathrm{p}=0.0037)$,

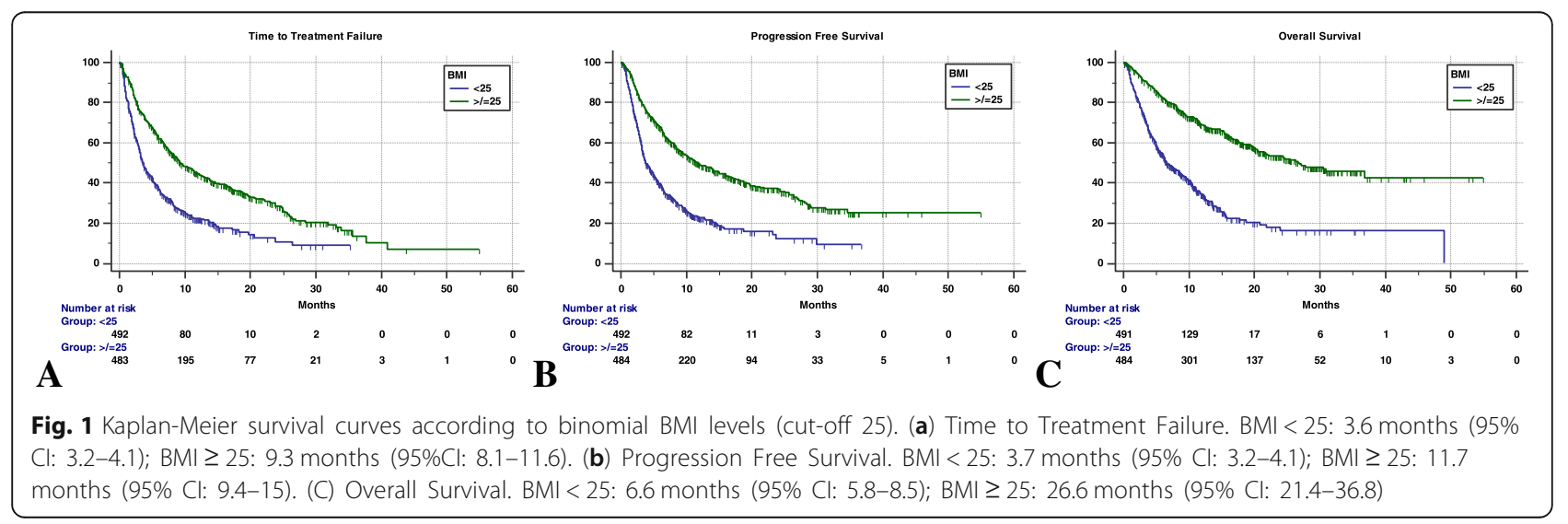


Table 2 Cox proportional-hazards regression: univariate and multivariate analyses of Time to Treatment Failure

\begin{tabular}{lll}
\hline & & Time to Treatment Failure \\
\cline { 2 - 3 } VARIABLE (Comparator) & Univariate Analysis & Multivariate Analysis \\
HR $(95 \%$ Cl); $p-$ value
\end{tabular}

${ }^{a}$ Weight was used as a continuous variable

Table 3 Cox proportional-hazards regression: univariate and multivariate analyses of Progression Free Survival

\begin{tabular}{|c|c|c|}
\hline & \multicolumn{2}{|c|}{ Progression Free Survival } \\
\hline & Univariate Analysis & Multivariate Analysis \\
\hline VARIABLE (Comparator) & HR $(95 \% \mathrm{Cl}) ; p$ - value & HR (95\% Cl); $p$-value \\
\hline $\begin{array}{l}\text { BMl } \\
\geq 25 \text { vs }<25\end{array}$ & $0.46(0.39-0.54) ; p<0.0001$ & $0.71(0.56-0.90) ; p<0.0001$ \\
\hline Weight ${ }^{\mathrm{a}}$ & $0.97(0.96-0.98) ; p<0.0001$ & $0.99(0.98-1.01) ; p=0.1580$ \\
\hline $\begin{array}{l}\text { irAEs of any grade } \\
\text { Yes vs No }\end{array}$ & $0.48(0.41-0.57) ; p<0.0001$ & $0.67(0.54-0.83) ; p=0.0002$ \\
\hline \multicolumn{3}{|l|}{ Primary Tumor (NSCLC) } \\
\hline Melanoma & $0.52(0.42-0.66) ; p<0.0001$ & $0.67(0.53-0.85) ; p=0.0008$ \\
\hline Kidney & $0.72(0.58-0.91) ; p=0.0062$ & $0.67(0.53-0.84) ; p=0.0008$ \\
\hline Others & $1.08(0.65-1.78) ; p=0.7556$ & $0.69(0.41-1.15) ; p=0.1533$ \\
\hline $\begin{array}{l}\text { Sex } \\
\quad \text { Male vs } \\
\text { Female }\end{array}$ & $1.20(1.01-1.42) ; p=0.0314$ & $1.03(0.86-1.22) ; p=0.7252$ \\
\hline $\begin{array}{l}\text { Age } \\
\text { Elderly vs } \\
\text { Non-elderly }\end{array}$ & $0.96(0.82-1.12) ; p=0.6394$ & - \\
\hline $\begin{array}{l}\text { Treatment line } \\
\text { Non-first vs First }\end{array}$ & $1.62(1.33-1.96) ; p<0.0001$ & $1.61(1.32-1.93) ; p<0.0001$ \\
\hline $\begin{array}{l}N^{\circ} \text { of metastatic sites } \\
>2 \mathrm{vs} \leq 2\end{array}$ & $1.46(1.27-1.68) ; p<0.0001$ & $1.42(1.21-1.67) ; p<0.0001$ \\
\hline $\begin{array}{l}\text { ECOG PS } \\
\geq 2 \text { vs } 0-1\end{array}$ & $2.60(2.13-3.17) ; p<0.0001$ & $2.06(1.67-2.52) ; p<0.0001$ \\
\hline
\end{tabular}


Table 4 Cox proportional-hazards regression: univariate and multivariate analyses of Overall Survival

\begin{tabular}{|c|c|c|}
\hline & \multicolumn{2}{|c|}{ Overall Survival } \\
\hline & Univariate Analysis & Multivariate Analysis \\
\hline $\begin{array}{l}\text { VARIABLE } \\
\text { (Comparator) }\end{array}$ & HR (95\% Cl); $p$ - value & HR (95\% Cl); $p$-value \\
\hline $\begin{array}{l}\text { BMl } \\
\geq 25 \text { vs }<25\end{array}$ & $0.33(0.28-0.41) ; p<0.0001$ & $0.49(0.38-0.64) ; p<0.0001$ \\
\hline Weight $^{\mathrm{a}}$ & $0.97(0.96-0.97) ; p<0.0001$ & $0.99(0.99-1.01) ; p=0.1884$ \\
\hline $\begin{array}{l}\text { irAEs of any grade } \\
\text { Yes vs No }\end{array}$ & $0.45(0.37-0.54) ; p<0.0001$ & $0.82(0.65-1.04) ; p=0.1085$ \\
\hline \multicolumn{3}{|l|}{ Primary Tumor (NSCLC) } \\
\hline Melanoma & $0.49(0.38-0.64) ; p<0.0001$ & $0.67(0.51-0.87) ; p=0.0036$ \\
\hline Kidney & $0.56(0.42-0.74) ; p=0.0001$ & $0.61(0.45-0.80) ; p=0.0005$ \\
\hline Others & $1.11(0.62-1.96) ; p=0.7337$ & $0.71(0.40-1.28) ; p=0.2632$ \\
\hline $\begin{array}{l}\text { Sex } \\
\quad \text { Male vs Female }\end{array}$ & $1.50(1.23-1.83) ; p<0.0001$ & $1.33(1.09-1.63) ; p=0.0044$ \\
\hline $\begin{array}{l}\text { Age } \\
\text { Elderly vs Non-elderly }\end{array}$ & $1.11(0.93-1.32) ; p=0.2401$ & - \\
\hline $\begin{array}{l}\text { Treatment line } \\
\text { Non-first vs First }\end{array}$ & $1.58(1.26-1.97) ; p=0.0001$ & $1.42(1.15-1.77) ; p=0.0012$ \\
\hline $\begin{array}{l}N^{0} \text { of metastatic sites } \\
>2 \text { vs } \leq 2\end{array}$ & $1.52(1.29-1.78) ; p<0.0001$ & $1.41(1.17-1.69) ; p=0.0002$ \\
\hline $\begin{array}{l}\text { ECOG PS } \\
\geq 2 \text { vs } 0-1\end{array}$ & $2.07(1.87-2.29) ; p<0.0001$ & $2.59(2.09-3.21) ; p<0.0001$ \\
\hline
\end{tabular}

${ }^{a}$ Weight was used as a continuous variable

PFS ( $\mathrm{p}=0.0132)$ and OS $(\mathrm{p}<0.0001)$, when compared to non-overweight patients.

Median TTF was not significantly different between overweight and obese patients $(10.3$ months [95\%CI: 8.2 - 4.1; 238 events] vs. 7.3 [95\%CI: 5.5 - 11.7; 80 events], $\mathrm{HR}=1.23$ [95\%CI: $0.95-1.58$ ], $\mathrm{p}=0.1087$ ). Similarly, we found no significant differences in median PFS (11.2 months [95\%CI: 9.1 - 15.6; 223 events patients] vs. 12.9 months [95\%CI: 7.1 - 18; 63 events], $\mathrm{HR}=0.99$ [95\%CI: $0.75-1.31$ ] $\mathrm{p}=0.9798)$ and median OS (26.6 months [95\%CI: 21.4 - 36.8; 223 censored patients] vs. not reached [63 censored patients], $\mathrm{HR}=1.04$ [95\%CI: $0.75-1.46$ ], $\mathrm{p}=0.7767$ ) between overweight and obese patients. Table 6 reports the univariate and multivariate analyses of TTF, PFS and OS, comparing overweight (non-obese) patients and obese patient with non-overweight patients. Figure 2 reports the Kaplan-Meier survival curves of obese, overweight and non-overweight patients.

When we analyzed the clinical outcomes of normal weight $v s$. underweight patients, we found a significantly longer median TTF (3.9 months [95\%CI: $3.4-5.0$; 327 events] vs. 1.8 [95\%CI: $1.7-2.9 ; 36$ events], $\mathrm{HR}=0.51$ [95\%CI: $0.35-0.71], \mathrm{p}=0.0001$ and median PFS (4.4 months [95\%CI: 3.6 - 5.3; 322 events] vs. 1.9 months [95\%CI: $1.7-2.9 ; 36$ events] $\mathrm{HR}=0.45$; 95\%CI: $0.32-0.64], \mathrm{p}<0.0001)$ in normal weight patients compared with underweight patients. We also found a significant prolonged median OS among normal weight compared to underweight patients (7.9 months [95\%CI: $6.4-9.8 ; 178$ censored patients] vs. 2.8 months [95\%CI: $1.8-3.6$; 4 censored patients], HR $=0.33$ [95\%CI: $0.23-0.48], \mathrm{p}<0.0001)$. Table 7 reports the univariate and multivariate analyses of TTF, PFS and OS, comparing overweight (non-obese) patients and obese patients with normal weight patients. Figure 3 reports the Kaplan-Meier survival curves of obese, overweight and normal weight patients.

\section{Discussion}

In this study we demonstrated that patients with a BMI $\geq 25$ experienced a better clinical outcome compared to those with a BMI $<25$. Recently, the association between BMI and OS of metastatic renal cell carcinoma patients, has been reported regardless of the use of anti-PD-1/PD-L1 therapy [4, 20]. However, in our study we found a strong correlation between overweight and improved clinical outcomes with anti-PD-1/PD-L1.

Some authors have already speculated about the negative impact of body composition alteration on immune cells activity [21]. Interestingly, it has been increasingly recognized that white adipose tissue, which is the most related to the fattening process [22], is also involved in the induction and/or coordination of host defenses, being a source of cytokines and chemokines [23]. In fact, adipose tissue modulates the Th1/Th2 balance, decreases 
Table 5 Cox proportional-hazards regression: univariate and multivariate analyses

\begin{tabular}{lll}
\hline A & Univariate Analysis & Multivariate Analysis \\
VARIABLE & HR $(95 \% \mathrm{Cl}) ; p$-value & HR $(95 \% \mathrm{Cl}) ; p$-value \\
\hline
\end{tabular}

Time to Treatment Failure

$\begin{array}{lll}\mathrm{BMl} & 0.54(0.45-0.66) ; p<0.0001 \quad 0.74(0.56-0.97) ; p=0.0330\end{array}$

Progression Free Survival

$\begin{array}{lll}\mathrm{BMl} & 0.49(0.40-0.59) ; p<0.0001 & 0.77(0.58-1.01) ; p=0.0668 \\ \geq 25 \text { vs }<25 & \end{array}$

$$
\text { Overall Survival }
$$

BMI $\quad 0.38(0.31-0.48) ; p<0.0001 \quad 0.59(0.43-0.81) ; p=0.0013$

$\geq 25$ vs $<25$

B Univariate Analysis Multiavariate Analysis

VARIABLE HR (95\% Cl); $p$-value HR $(95 \% \mathrm{Cl})$; $p$-value

Time to Treatment Failure

BMl $\quad 0.45(0.35-0.61) ; p<0.0001 \quad 0.51(0.32-0.80) ; p=0.0037$

$\geq 25$ vs $<25$

Progression Free Survival

BMI $\quad 0.41(0.31-0.56) ; p<0.0001 \quad 0.56(0.35-0.88) ; p=0.0132$

$\geq 25$ vs $<25$

Overall Survival

BMI $\quad 0.25(0.17-0.36) ; p<0.0001 \quad 0.27(0.15-0.48) ; p<0.0001$

$\geq 25$ vs $<25$

(A) male patients (B) female patients. The used covariates (not shown) were: weight (continuous), irAEs of any grade, primary tumors, line of treatment, ECOG-PS, number of metastatic sites

Table 6 Cox proportional-hazards regression: univariate and multivariate analyses according to non-overweight $(<25)$, overweight (25-30) and obese ( $\geq 30$ ) BMl levels

\begin{tabular}{|c|c|c|}
\hline & Univariate Analysis & Multivariate Analysis \\
\hline $\begin{array}{l}\text { VARIABLE } \\
\text { (Comparator) }\end{array}$ & HR $(95 \% \mathrm{Cl}) ; p$-value & HR $(95 \% \mathrm{Cl}) ; p$-value \\
\hline $\begin{array}{l}\mathrm{BMI} \\
(<25)\end{array}$ & \multicolumn{2}{|c|}{ Time to Treatment Failure } \\
\hline $\begin{array}{l}25-30 \\
\geq 30\end{array}$ & $\begin{array}{l}0.49(0.41-0.58) ; p<0.0001 \\
0.60(0.47-0.77) ; p=0.0001\end{array}$ & $\begin{array}{l}0.67(0.53-0.84) ; p=0.0008 \\
0.86(0.61-1.24) ; p=0.4414\end{array}$ \\
\hline $\begin{array}{l}\mathrm{BMl} \\
(<25)\end{array}$ & \multicolumn{2}{|c|}{ Progression Free Survival } \\
\hline $\begin{array}{l}25-30 \\
\geq 30\end{array}$ & $\begin{array}{l}0.46(0.39-0.55) ; p<0.0001 \\
0.46(0.35-0.61) ; p<0.0001\end{array}$ & $\begin{array}{l}0.71(0.56-0.89) ; p=0.0044 \\
0.80(0.55-1.17) ; p=0.2669\end{array}$ \\
\hline $\begin{array}{l}\text { BMl } \\
(<25)\end{array}$ & \multicolumn{2}{|c|}{ Overall Survival } \\
\hline $\begin{array}{l}25-30 \\
\geq 30\end{array}$ & $\begin{array}{l}0.33(0.27-0.41) ; p<0.0001 \\
0.34(0.25-0.48) ; p<0.0001\end{array}$ & $\begin{array}{l}0.49(0.37-0.64) ; p<0.0001 \\
0.61(0.39-0.94) ; p=0.0258\end{array}$ \\
\hline
\end{tabular}

The used covariates (not shown) were: weight (continuous), irAEs of any grade, primary tumors, sex, line of treatment, ECOG-PS, number of metastatic sites
Table 7 Cox proportional-hazards regression: univariate and multivariate analyses according to normal weight (18.5-25), overweight (25-30) and obese ( $\geq 30$ ) BMl levels

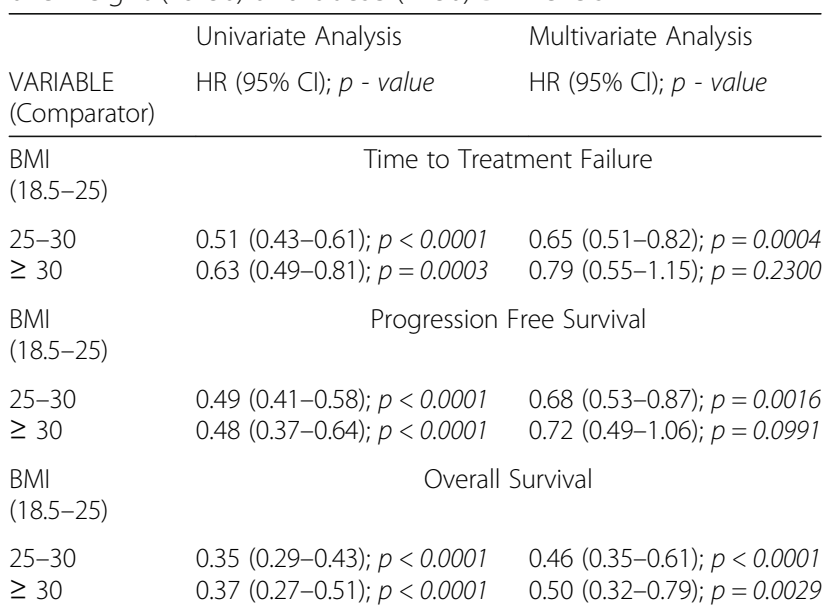

The used covariates (not shown) were: weight (continuous), irAEs of any grade, primary tumors, sex, line of treatment, ECOG-PS, number of metastatic sites

the activation of Treg through adiponectin, increases pro-inflammatory macrophages, activates T-cells with the binding between LIGHT-HVEM (herpesvirus entry mediator) and increases the inflammatory status through CD40 pathway [24-26].

Moreover, a recent preclinical study revealed that white adipose tissue might also play a role in immune homeostasis [27]. In this study, white adipose tissue of mice was reported to accumulate pathogen-specific memory T-cells after a microbial infection, including tissue-resident cells expressing a distinct metabolic profile. Intriguingly, these data support the hypothesis that adipose tissue can act as a reservoir of tissue-specific memory T-cells, which can undergo a rapid response to reactivation against exogenous stimuli. This evidence raises an interesting question, can these adipose tissuespecific T-cells be promptly reactivated against cancerspecific antigens as they do against microbial antigens?

In a recent meta-analysis of patients with immune-mediated inflammatory diseases treated with anti-TNF (tumor necrosis factor), the authors reported a trend towards a lower response rate to treatment among overweight patients [28]. This is likely to reflect the reduced responsivity of T-cells of obese individuals, which has also been confirmed in preclinical models showing a significant increase in dysfunctional exhausted T-cells in obese mice [9]. Nevertheless, such inflamed and immune-exhausted status may be more likely susceptible to the immune checkpoint blockade. In support of this, in preclinical models, T-cell dysfunction in obese mice was proven to be partly mediated by the PD- 1 axis and driven by leptin, strengthening the already known correlation between JAK/STAT pathway and immune checkpoint inhibition [9, 29]. 

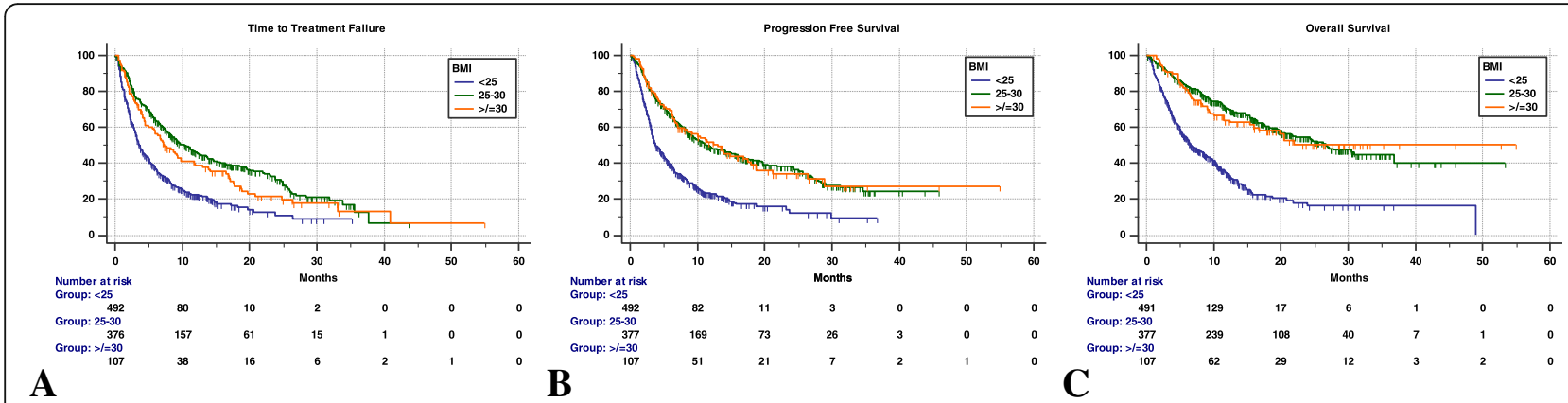

Fig. 2 Kaplan-Meier survival curves according to BMl levels (non-overweight BMl $<25$, overweight BMI 25-30, obese BMI $\geq 30$ ). (a) Time to Treatment Failure. BMI < 25: 3.6 months (95\% Cl: 3.2-4.1); BMl 25-30: 10.3 months (95\%Cl: 8.2-4.1); BMI $\geq 30$ : 7.3 months (95\%Cl: $5.5-11.7)$. (b) Progression Free Survival. BMI < 25: 3.7 months (95\% Cl: 3.2-4.1); BMI 25-30: 11.2 months (95\%Cl: 9.1-15.6); BMI $\geq 30: 12.9$ months (95\%Cl: $7.1-18$ ). (c) Overall Survival. BMI < 25: 6.6 months (95\% Cl: 5.8-8.5); BMI 25-30: 26.6 months (95\%Cl: 21.4-36.8); BMI $\geq 30$ : not reached

Importantly, in our study we also found a significantly higher incidence of irAEs of any grade among overweight/ obese patients. In light of the emerging association between the development of irAEs and improved clinical outcomes with ICIs across different tumor types, our findings are not unexpected [30-35]. In our cohort, the development of irAEs of any grade was independently associated with improved clinical outcomes along with a BMI $\geq 25$ in multivariate analyses.

The analysis performed by separating overweight and obese patients, demonstrated that a linear relationship between BMI and positive outcomes cannot be assumed. Even though we found no statistically significant differences in TTF, PFS and OS between overweight and obese patients, when separately comparing obese patients to non-overweight patients (Table 6), we observed the loss of significance regarding TTF and PFS, while not regarding OS. This result is of particular interest, considering the possibility of a negative impact on survival of obese patients due to cardiovascular and metabolic complications of obesity itself. Noteworthy, the HRs are concordantly lower for overweight (non-obese) patients in each survival analysis, compared to obese patients, thus supporting the hypothesis that the prognostic weight of obesity, could have partially influenced the final results.

On the other hand, despite the small sample size (4.1\% of the entire population), underweight patients had significantly shorter TTF, PFS and OS, when compared to normal weight patients, confirming that malnutrition (and cachexia) is an independent negative prognostic factor. Nonetheless, when we compared obese and overweight patients (Table 7) with normal weight patients we observed significantly improved clinical outcomes favouring the overweight group, which suggests that overweightness has a direct impact on the efficacy of ICIs.

In our study we also carried a gender-based analysis. Previously, it has been reported that female patients tend to have lower benefit from ICI compared to males [36, 37]. However, whether the gender plays a key role in determining the clinical outcome to immunotherapy is still in need of further investigation. In our study, we found that overweight female patients derived a greater clinical benefit form immunotherapy as compared to the male counterpart (Table 5). However, it should be highlighted that

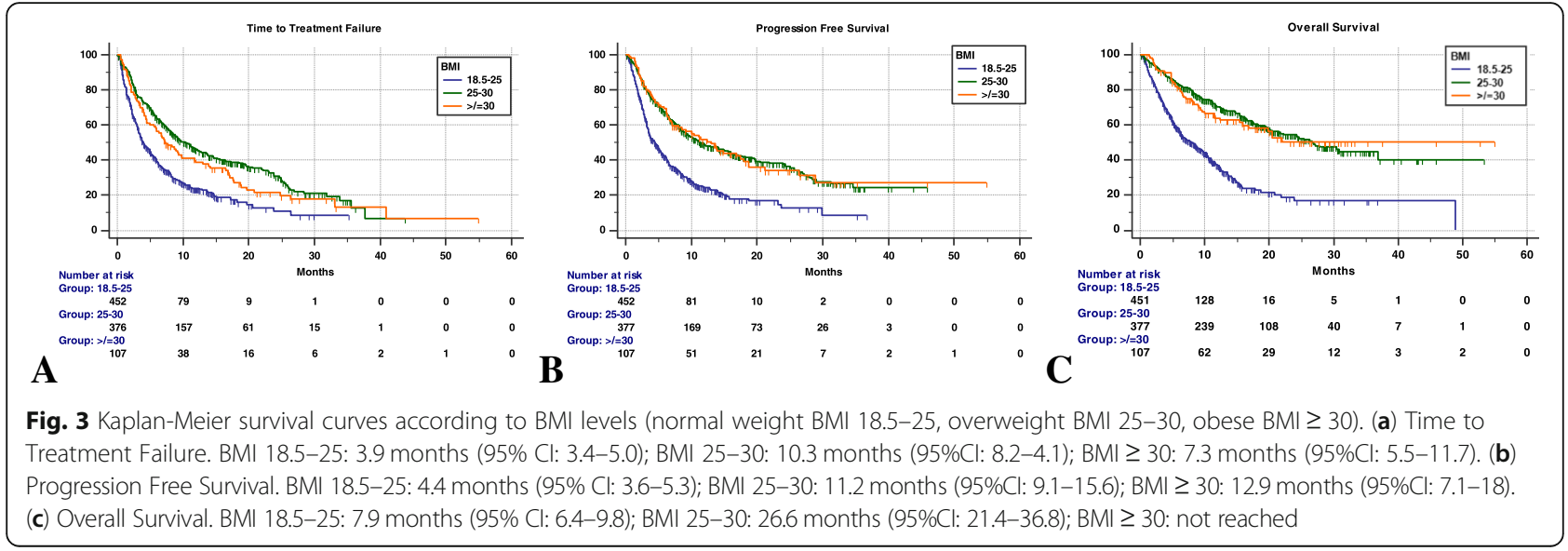


overweightness was associated with improved outcomes in both males and females in the multivariate analysis. This led us to speculate that in our population the predictive role of BMI was to be stronger than the predictive role of gender.

Certainly, the relationship between sex, adipose tissue and immunity is complex and ambiguous. Sex-hormones, in particular estrogens, could affect adipose tissue functions [38], but in some respects their influence on the immune systems does not seem unidirectional [39]. Furthermore, the median age of female patients in our study was 67 , indicating a prevalence of postmenopausal patients. In this specific population the adipose tissue becomes a major source of circulating estrogens [40].

Another way to explain how BMI might affect sex hormones levels and the immune response, is through diet regimens which underpin the weight gain. Indeed, gut microbiota may be influenced by the different "modifying pressures" of various diet types. Interestingly, males and females have recently been reported to have gender-specific differences in their immune system and gut microbiota composition. Whether these differences in gut microbiota composition might impact the efficacy or the safety profile of immunotherapy is subject of intense research and is expected to provide us further insight in the optimal management of our patients [41-43].

Our study is certainly flawed by several caveats, including the retrospective design with the risk of selection and data collection biases, the heterogeneity of the analyzed population, the lack of a centralized imaging review for response assessment and the lack of data about patient comorbidities. In addition, the lack of control group of patients who did not received ICIs further limit the power of our analysis. On the other hand, a unique strength of our study is that we evaluated the predictive role of baseline assessment of BMI in a "real life" population of individuals candidate to receive ICIs.

\section{Conclusion}

In this study we demonstrated that patients with a BMI $\geq 25$ experienced better clinical outcomes with anti-PD-1/PD-L1 agents, compared to those with a BMI $<25$. Our results suggest that BMI could be a useful predictive tool in clinical practice as well as a reliable stratification variable for prospective clinical trials with ICIs.

\section{Additional files}

Additional file 1: List of oncological institutions of the study. (DOCX $15 \mathrm{~kb}$ )

Additional file 2: Immune-related adverse events of any grade and G3/G4 immune-related adverse events. (DOCX 15 kb)

Additional file 3: Univariate and multivariate analyses with logistic regression of Objective Response Rate. (DOC 49 kb)

\section{Acknowledgements}

This work was supported by the Consorzio Interuniversitario Nazionale per la Bio-Oncologia (CINBO).

\section{Funding}

No funding was received.

\section{Availability of data and materials}

The datasets used during the present study are available from the corresponding author upon reasonable request.

\section{Authors' contributions}

All authors contributed to the publication according to the ICMJE guidelines for the authorship. All authors read and approved the manuscript and agree to be accountable for all aspects of the research in ensuring that the accuracy or integrity of any part of the work are appropriately investigated and resolved.

\section{Ethics approval and consent to participate}

All patients provided written, informed consent to treatment with immunotherapy. All patients alive at the time of data collection provided an informed consent for the present retrospective analysis. The procedures followed were in accordance with the precepts of Good Clinical Practice and the declaration of Helsinki. The study was approved by the respective local ethical committees on human experimentation of each institution, after previous approval by the coordinating center (University of L'Aquila, Internal Review Board protocol number 32865, approved on July $24^{\text {th }}, 2018$ ).

\section{Consent for publication}

Not applicable.

\section{Competing interests}

Dr Alessio Cortellini received grants as speaker by MSD, Astra-Zeneca and Boehringer Ingelheim, gran consultancies by BMS and Ipsen; dr Marcello Tiseo received grant as speaker and advisory role by Astra-Zeneca, Pfizer, EliLilly, BMS, Novartis, Roche, MSD, Boehringer Ingelheim, Otsuka, Pierre Fabre; dr Maria Giuseppa Vitale received travel grants and speaker fees by BMS, Ipsen Astellas, Jansen, Novartis and Pfizer; dr Sebatiano Buti received grants as speaker and advisory role by BMS, Pfizer, MSD, Ipsen, Novartis, AstraZeneca; dr. Melissa Bersanelli received honoraria as speaker at scientific events and as consultant for advisory role by BMS and Pfizer.

\section{Publisher's Note}

Springer Nature remains neutral with regard to jurisdictional claims in published maps and institutional affiliations.

\section{Author details}

${ }^{1}$ Medical Oncology, St. Salvatore Hospital, L'Aquila, Italy. ${ }^{2}$ Department of Biotechnological and Applied Clinical Sciences, University of L'Aquila, L'Aquila, Italy. ${ }^{3}$ Medical Oncology, University Hospital of Parma, Parma, Italy. ${ }^{4}$ Department of Medicine and Surgery, University of Parma, Parma, Italy.

${ }^{5}$ Medical Oncology, Campus Bio-Medico University, Rome, Italy. ${ }^{6}$ Department of Clinical and Molecular Medicine, Sant'Andrea Hospital, Sapienza University of Rome, Rome, Italy. ${ }^{7}$ Clinical Oncology Unit, S.S. Annunziata Hospital, Chieti, Italy. ${ }^{8}$ Department of Medical, Oral \& Biotechnological Sciences University G. D’Annunzio, Chieti-Pescara, Italy. ${ }^{9}$ Medical Oncology, Santa Maria Goretti Hospital, Latina, Italy. ${ }^{10}$ Department of Oncology, University Hospital of Pisa, Istituto Toscano Tumori, Pisa, Italy. ${ }^{11}$ Medical Oncology, "Santo Spirito" Hospital, Pescara, Italy. ${ }^{12}$ Istituto Dermopatico dell'Immacolata, IDI-IRCCS, Rome, Italy. ${ }^{13}$ Medical Oncology, University Hospital of Modena, Modena, Italy. ${ }^{14}$ Medical Oncology, Fermo Area Vasta 4, Fermo, Italy. ${ }^{15}$ Oncology Clinic, Università Politecnica delle Marche, Ospedali Riuniti di Ancona, Ancona, Italy.

${ }^{16}$ Medical Oncology, AV2 Fabriano ASUR Marche, Pescara, Italy. ${ }^{17}$ Medical

Oncology Unit, University Hospital of Cagliari, Cagliari, Italy. ${ }^{18}$ Medical

Oncology, Santa Maria della Misericordia Hospital, Perugia, Italy. ${ }^{19}$ Pulmonary

Oncology Unit, St. Camillo Forlanini Hospital, Rome, Italy. ${ }^{20}$ Medical Oncology

(B), Policlinico Umberto I, "Sapienza" University of Rome, Rome, Italy.

${ }^{21}$ Dermatology, San Salvatore Hospital, L'Aquila, Italy. ${ }^{22}$ Melanoma, Cancer Immunotherapy and Development Therapeutics Unit, Istituto Nazionale Tumori-IRCCS Fondazione "G. Pascale", Naples, Italy. ${ }^{23}$ Medical Oncology Unit, 
St. Salvatore Hospital, Department of Biotechnological and Applied Clinical Sciences, University of L'Aquila, Via Vetoio, 67100 L'Aquila, Italy.

\section{Received: 4 December 2018 Accepted: 5 February 2019 Published online: 27 February 2019}

\section{References}

1. Laviano A, Koverech A, Mari A. Cachexia: clinical features when inflammation drives malnutrition. Proc Nutr Soc. 2015 Nov;74(4):348-54.

2. Taghizadeh $\mathrm{N}$, Boezen HM, Schouten, et al. BMI and lifetime changes in BMI and cancer mortality risk. PLoS One. 2015;10(4):e0125261. https://doi.org/10. 1371/journal.pone.0125261 eCollection 2015

3. Lennon $H$, Sperrin $M$, Badrick $E$, et al. The obesity paradox in Cancer: a review. Curr Oncol Rep. 2016;18(9):56. https://doi.org/10.1007/ s11912-016-0539-4.

4. Albiges $L$, Hakimi AA, Xie W, et al. Body mass index and metastatic renal cell carcinoma: clinical and biological correlations. J Clin Oncol. 2016;34(30):3655-63. https://doi.org/10.1200/JCO.2016.66.7311.

5. Antoun S, Bayar A, lleana E, et al. High subcutaneous adipose tissue predicts the prognosis in metastatic castration-resistant prostate cancer patients in post chemotherapy setting. Eur J Cancer. 2015;51(17):2570-7. https://doi. org/10.1016/j.ejca.2015.07.042 Epub 2015 Aug 13.

6. McQuade JL, Daniel CR, Hess KR, et al. Association of body-mass index and outcomes in patients with metastatic melanoma treated with targeted therapy, immunotherapy, or chemotherapy: a retrospective, multicohort analysis. Lancet Oncol. 2018;19(3):310-22 Epub 2018 Feb 12.

7. Heidelberger V, Goldwasser F, Kramkimel N, et al. Sarcopenic overweight is associated with early acute limiting toxicity of anti-PD1 checkpoint inhibitors in melanoma patients. Investig New Drugs. 2017;35(4):436-41. https://doi.org/10.1007/s10637-017-0464-x Epub 2017 Apr 10.

8. Richtig G, Hoeller C, Wolf M, et al. Body mass index may predict the response to ipilimumab in metastatic melanoma: An observational multicentre study. PLoS One. 2018 ;13(10):e0204729. https://doi.org/10.1371/ journal.pone.0204729. eCollection 2018.13.

9. Wang Z, Aguilar EG, Luna Jl, et al. Paradoxical effects of obesity on T cell function during tumor progression and PD-1 checkpoint blockade. Nat Med. 2018. https://doi.org/10.1038/s41591-018-0221-5 [Epub ahead of print]

10. Minana B, Cozar JM, Palou J, et al. Bladder cancer in Spain 2011: populationbased study. J Urol. 2014;191(2):323-8.

11. Ciocan D, Barbe C, Aubin F, et al. Distinctive features of melanoma and its management in elderly patients: a population-based study in France. JAJA Dermatol. 2013;149(10):1150-7.

12. Gridelli C, Balducci L, Ciardiello F, et al. Treatment of elderly patients with nonsmall-cell lung Cancer: results of an international expert panel meeting of the Italian Association of Thoracic Oncology. Clin Lung Cancer. 2015;16(5):325-33.

13. Azawi NH, Joergensen SM, Jensen NV, et al. Trends in kidney cancer among the elderly in Denmark, 1980-2012. Acta Oncol. 2016;55(Suppl 1):79-84.

14. Eisenhauer EA, Therasse $P$, Bogaerts J, et al. New response evaluation criteria in solid tumours: revised RECIST guideline (version 1.1). Eur J Cancer. 2009:45:228-47.

15. Mantel N. Chi-square tests with one degree of freedom: extensions of the Mendel-Haenszel procedure. J Am Stat Assoc. 1963;58:690-700.

16. Hosmer DW Jr, Lemeshow S, Sturdivant RX. Applied logistic regression. Third Edition. New Jersey: John Wiley \& Sons (2013).

17. Kaplan EL, Meier P. Nonparametric estimation of incomplete observations. J Am Stat Assoc. 1958;53:457-81

18. Schemper M, Smith TL. A note on quantifying follow-up in studies of failure time. Control Clin Trials. 1997;17:343-6.

19. Cox DR. Regression models and life tables (with discussion). J R Stat Soc Ser B. 1972;74(187-200)

20. Goebell PJ, Müller L, Hübner A, et al. Body mass index as independent predictor of overall survival in patients with advanced renal cell carcinoma at start of systemic treatment-Analyses from the German clinical RCCRegistry. Urol Oncol. 2018;(10):470.e1-9. https://doi.org/10.1016/j.urolonc 2018.07.007 Epub 2018 Aug 18.

21. Lutz CT, Quinn LS. Sarcopenia, obesity, and natural killer cell immune senescence in aging: altered cytokine levels as a common mechanism. Aging (Albany NY). 2012:4(8):535-46.

22. Sutherland LN, Capozzi LC, Turchinsky NJ, et al. Time course of high-fat diet-induced reductions in adipose tissue mitochondrial proteins: potential mechanisms and the relationship to glucose intolerance. Am J
Physiol Endocrinol Metab. 2008;295(5):E1076-83. https://doi.org/10.1152/ ajpendo.90408.2008 Epub 2008 Sep 9.

23. Ouchi N, Parker JL, Lugus JJ, et al. Adipokines in inflammation and metabolic disease. Nat Rev Immunol. 2011;11(2):85-97. https://doi.org/10. 1038/nri2921. Epub 2011 Jan

24. Jordan BF, Gourgue F, Cani PD. Adipose Tissue metabolism and Cancer progression: novel insights from gut microbiota? Curr Pathobiol Rep. 2017;5(4):315-22. https://doi.org/10.1007/s40139-0170154-6 Epub 2017 Oct 24.

25. Magrone T, Jirillo E. Childhood obesity: immune response and nutritional approaches. Front Immunol. 2015;6:76. https://doi.org/10.3389/fimmu.2015. 00076 eCollection 2015.

26. Seijkens T, Kusters P, Chatzigeorgiou A, Chavakis T, Lutgens E. Immune cell crosstalk in obesity: a key role for costimulation? Diabetes. 2014;63(12): 3982-91. https://doi.org/10.2337/db14-0272.

27. Han SJ, Glatman Zaretsky A, Andrade-Oliveira V, et al. White Adipose Tissue Is a Reservoir for Memory T Cells and Promotes Protective Memory Responses to Infection. Immunity. 2017;47(6):1154-1168.e6. https://doi.org/ 10.1016/j.immuni.2017.11.009 Epub 2017 Dec 5.

28. Singh $S$, Facciorusso $A$, Singh $A G$, et al. Obesity and response to antitumor necrosis factor-a agents in patients with select immunemediated inflammatory diseases: a systematic review and metaanalysis. PLoS One. 2018;13(5):e0195123. https://doi.org/10.1371/ journal.pone.0195123

29. Mullen M, Gonzalez-Perez RR. Leptin-Induced JAK/STAT Signaling and Cancer Growth. Vaccines (Basel). 2016;4(3). pii: E26. doi: https://doi.org/10. 3390/vaccines4030026

30. Sanlorenzo M, Vujic I, Daud A, et al. Pembrolizumab Cutaneous Adverse Events and Their Association With Disease Progression JAMA Dermatol. 2015:151(11):1206-12. https://doi.org/10.1001/jamadermatol.2015.1916.

31. Freeman-Keller M, Kim Y, Cronin H, et al. Nivolumab in resected and Unresectable metastatic melanoma: characteristics of immune-related adverse events and association with outcomes. Clin Cancer Res. 2016;22(4): 886-94. https://doi.org/10.1158/1078-0432.CCR-15-1136.

32. Min Lee CK, Li S, Tran DC, et al. Characterization of dermatitis after PD-1/PD11 inhibitor therapy and association with multiple oncologic outcomes: A retrospective case-control study. J Am Acad Dermatol. 2018. pii: S01909622(18)30831-4. doi: https://doi.org/10.1016/j.jaad.2018.05.035. [Epub ahead of print].

33. Osorio JC, Ni A, Chaft JE, et al. Antibody-mediated thyroid dysfunction during T-cell checkpoint blockade in patients with non-small-cell lung cancer. Ann Oncol. 2017;28(3):583-9. https:/doi.org/10.1093/annonc/mdw640.

34. Haratani K, Hayashi H, Chiba Y, et al. Association of Immune-Related Adverse Events with Nivolumab Efficacy in non-small-cell lung Cancer. JAMA Oncol. 2018:4(3):374-8. https://doi.org/10.1001/jamaoncol.2017.2925.

35. Teraoka S, Fujimoto D, Morimoto T, et al. Early immune-related adverse events and association with outcome in advanced non-small cell lung Cancer patients treated with Nivolumab: a prospective cohort study. J Thorac Oncol. 2017;12(12):1798-805. https://doi.org/10.1016/j.jtho.2017.08. 022 Epub 2017 Sep 20

36. Conforti F, Pala L, Bagnardi V, et al. Cancer immunotherapy efficacy and patients' sex: a systematic review and meta-analysis. Lancet Oncol. 2018;19(6):737-46. https://doi.org/10.1016/S1470-2045(18)302614 Epub 2018 May 16.

37. Botticelli A, Onesti CE, Zizzari l, et al. The sexist behaviour of immune checkpoint inhibitors in cancer therapy? Oncotarget. 2017;8(59):99336-46. https://doi.org/10.18632/oncotarget.22242.

38. Pallottini V, Bulzomi P, Galluzzo P, et al. Estrogen regulation of adipose tissue functions: involvement of estrogen receptor isoforms. Infect Disord Drug Targets. 2008 Mar;8(1):52-60.

39. Khan D, Ahmed SA. The Immune System Is a Natural Target for Estrogen Action: Opposing Effects of Estrogen in Two Prototypical Autoimmune Diseases. Front Immunol. 2015;6:635. https://doi.org/10. 3389/fimmu.2015.00635.

40. Stocco C. Tissue Physiology and Pathology of Aromatase Steroids. 2012 Jan; 77(1-2): 27-35. Published online 2011 Nov 13. doi: https://doi.org/10.1016/j. steroids.2011.10.013

41. Markle JG, Frank DN, Mortin-Toth S, Robertson CE, Feazel LM, RolleKampczyk $U$, et al. Sex differences in the gut microbiome drive hormonedependent regulation of autoimmunity. Science (2013) 339(6123):1084-8. https://doi.org/10.1126/science.1233521. 
42. Yurkovetskiy L, Burrows $M$, Khan AA, Graham L, Volchkov P, Becker L, et al. Gender bias in autoimmunity is influenced by microbiota. Immunity. 2013; 39(2):400-12. https://doi.org/10.1016/j.immuni.2013.08.013.

43. Routy B, Le Chatelier E, Derosa L, et al. Gut microbiome influences efficacy of PD-1-based immunotherapy against epithelial tumors. Science. 2018; 359(6371):91-7. https://doi.org/10.1126/science.aan3706.

Ready to submit your research? Choose BMC and benefit from:

- fast, convenient online submission

- thorough peer review by experienced researchers in your field

- rapid publication on acceptance

- support for research data, including large and complex data types

- gold Open Access which fosters wider collaboration and increased citations

- maximum visibility for your research: over $100 \mathrm{M}$ website views per year

At $\mathrm{BMC}$, research is always in progress.

Learn more biomedcentral.com/submissions 